\title{
Genetic aspects of autosomal dominant late onset cerebellar ataxia
}

\author{
A E HARDING* \\ From the MRC Clinical Genetics Unit, Institute of Child Health, London WCIN IEH
}

SUMMARY The genetic features of eight families with autosomal dominant late onset cerebellar $\overrightarrow{\widetilde{\omega}}$ ataxia with randomly distributed associated clinical features are described. The ratio of affected to unaffected offspring of affected subjects was not significantly different from $1: 1$. The mutant gene was fully penetrant when cases who died before the period of risk of developing the disease were $\overrightarrow{0}$ excluded. The proportion of new mutants with this disorder appears to be low. Biological fitness was not impaired. Affected females tended to have larger families than affected males. The ages of $\tilde{\sigma}_{-}$ onset of females and males were not significantly different, but the offspring of affected males hado earlier ages of onset and death than those of affected females. A cumulative age of onset curve is $\rightarrow$ presented which should aid genetic counselling of subjects at risk and their children.

The first report of hereditary ataxia was that of Friedreich in $1863 .^{1}$ Little can be added to Friedreich's careful clinical and pathological descriptions today. The disease he described is a well recognised clinical syndrome, characterised by an age of onset usually before 20 years, dysarthria, cerebellar ataxia, and tendon areflexia. Pyramidal signs and loss of deep sensation are frequent. ${ }^{2}$ Inheritance is autosomal recessive. ${ }^{3}$ Friedreich's ataxia is the commonest of the hereditary ataxias. The other more infrequent disorders are nosologically confused.

In 1893, Marie ${ }^{4}$ drew attention to a group of families reported who suffered from a hereditary ataxia distinct from that described by Friedreich. It differed in that the age of onset was later, the tendon reflexes were usually increased, and inheritance was sometimes autosomal dominant. It was pointed out by Holmes ${ }^{5}$ that the cases described by Marie were clinically and pathologically heterogeneous. Holmes rightly considered that the term 'Marie's ataxia', a term still in use today, should be rejected for this reason. The classification of the late onset dominantly inherited cerebellar ataxias has since remained confused. Attempts at classification have usually been based on pathological findings and reported cases have been divided into cases of olivopontocerebellar atrophy (OPCA), cerebello-olivary

* Present address: Department of Neurology, The Middlesex Hospital, Mortimer Street, London W1.

Received for publication 5 January 1981 degeneration, and parenchymatous cortical cerebellar atrophy. These categories are somewhat unsatisfactory for several reasons. Evidence of $œ$ clinical and genetic heterogeneity tends to te. ignored. $^{6}$ The names of these pathological entities are rather misleading as often other structures, such as the spinal cord and the basal ganglia, are involved in the degenerative process. ${ }^{7}$ Also, when necropsies have been performed on more than one member of a $\frac{D}{\triangleright}$ family, the findings are by no means always con- $\vec{F}$ cordant. $^{8-11}$

From the clinical point of view classification has been equally difficult, mainly because of considerable intrafamilial variation. The most variable aspects of these disorders are the presence or absence of $\overline{3}$ associated features, in addition to cerebellar ataxia, ${ }^{\circ}$ in different family members. These associated 3 features include ophthalmoplegia, optic atrophy, dementia, extrapyramidal signs such as chorea and 3 facial impassivity, pigmentary retinal degeneration, 0 and amyotrophy. It is clear from examination? of previously published reports that the number of $\frac{D}{O}$ additional features increases with the number of patients studied per family..$^{12}$ The tendon reflexes $N$ may be increased or depressed in members of the $N$ same family ${ }^{1314}$ which makes classification on the N basis of reflex changes impossible, contrary to previous suggestions. ${ }^{15}$

Konigsmark and Weiner ${ }^{7}$ divided previously을 reported necropsy-proven cases of OPCA into five groups on the basis of minor pathological differences together with clinical features such as the associations 
mentioned above and tendon reflex changes. These were as follows: OPCA I, with dysarthria, tremor, sensory loss, involuntary movements, and pyramidal signs; OPCA II, an autosomal recessive group which need not be discussed further here; OPCA III, with retinal degeneration; OPCA IV, with laryngeal and facial palsy, dysphagia, and hypoactive or hyperactive reflexes; OPCA V, with ophthalmoplegia, dementia, and extrapyramidal signs. The original reports which Konigsmark and Weiner reviewed would suggest considerable overlap between these categories. The authors omitted two families with markedly discordant neuropathological features, and put the patients described by Gray and Oliver ${ }^{16}$ and Schut and Haymaker ${ }^{10} 13$ in groups I and IV, respectively. They were all members of the same family.

There is very little evidence in published reports to suggest that patients with cerebellar ataxia in association with ophthalmoplegia, optic atrophy, dementia, extrapyramidal features, or amyotrophy can be subdivided further. These families have been reported in the past as examples of hereditary cerebellar ataxia, ${ }^{16}$ hereditary spastic paraplegia 'plus', ${ }^{17}$ 'resembling multiple sclerosis', ${ }^{12} 18$ OPCA, spinopontine atrophy, ${ }^{19}{ }^{20}$ and cerebello-olivary atrophy. ${ }^{21}$ There are reasonable clinical grounds to suggest that Azorean ataxia might be included in this group. ${ }^{22} 23$ The intrafamilial variation in tendon reflex changes is probably the result of the fact that the reflexes tend to become depressed as the disease progresses. ${ }^{131424}$ Families containing subjects with cerebellar ataxia and pigmentary retinal degeneration are likely to be clinically and genetically distinct from those with other associations. One striking feature of this particular association is its marked concordance within families. ${ }^{25-27}$ The age of onset is slightly earlier, usually between 12 and 30 years, whereas in families with other associated features onset is mainly in the fourth and fifth decades. ${ }^{7}$

In a recent study of 11 families with autosomal dominant cerebellar ataxia, ${ }^{24}$ intrafamilial correlation of age of onset and an assessment of clustering of clinical features within families using $\chi^{2}$ tests confirmed the impression that there is little evidence of genetic heterogeneity in kindreds where ophthalmoplegia, optic atrophy, dementia, extrapyramidal features, and amyotrophy are found in affected subjects. These features appeared to be randomly distributed among the affected members of eight families. The three other families contained patients with clinically distinct syndromes which were: cerebellar ataxia with pigmentary retinal degeneration, a later onset (over 60 years) 'pure' cerebellar syndrome, and an ataxic disorder associated with myoclonus and deafness. This paper presents the genetic features of the eight families with 'randomly distributed' additional features.

\section{Patients and methods}

The eight families were investigated as part of a clinical and genetic study of 200 families with progressive cerebellar and spinocerebellar degenerations. The latter families contained 234 index cases which were ascertained from the medical records departments of The National Hospitals for Nervous Diseases, The Hospital for Sick Children, Great Ormond Street, other London neurological centres, and the records of the Friedreich's Ataxia Group. Patients were included in the study if they had attended hospital during the period 1966 to 1980 and lived within a 50 mile radius of central London. Co-operative subjects were visited at home or in hospital by the author. A detailed history was taken which included details of first and second degree relatives. Full neurological and general examinations, 12 lead electrocardiography, and urine testing were performed on the index cases. As many first degree relatives as possible were seen and examined.

The cases were initially divided into six major categories for the purpose of further analysis. These were as follows: (1) Friedreich's ataxia (as defined clinically by Tyrer, ${ }^{28}$ Geoffroy et $a l,{ }^{2}$ and other workers) (90 families); (2) progressive ataxia developing within the first two decades associated with dysarthria and generally normal or increased tendon reflexes (20 families); (3) hereditary spastic paraplegia (29 families); (4) late onset cerebellar ataxia of autosomal dominant inheritance (11 families); (5) single cases of late onset cerebellar ataxia (36 families); and (6) other syndromes. The patients reported here are some of those in the fourth category.

The diagnostic criterion for inclusion in this group was the presence of a progressive, unremitting cerebellar ataxia, with or without other associated features, developing over the age of 20 years in the majority of affected subjects in a given family. Inheritance was autosomal dominant. There were 11 families in the group, of which three were clinically and genetically distinct from the remaining eight The former included one family with retinal degeneration and one each of the rare syndromes (a pure disorder and one associated with myoclonus and deafness) mentioned in the introduction. The eight families reported here had randomly distributed associated clinical features, of which supranuclear ophthalmoplegia and dementia were the commonest. Their clinical features and pedigrees have been reported elsewhere. ${ }^{24}$ There were nine index cases. A further three affected subjects were examined by the 
author and two relatives at risk of developing the disease had slightly suspicious clinical signs (mild ataxia on tandem walking). Another 48 relatives were known to be affected but were dead or unavailable for study. Reliable clinical information was obtained for 17 of them and data concerning age of onset for another 30 . Some of the patients studied were descendants of 'the Drew family of Walworth' described by Ferguson and Critchley in 1929.12 Thirteen first degree relatives of index cases were examined and found to be normal. The main age of onset of the disorder was $37.83 \pm 7.27$ (range 18 to 65 ) years. In those patients who had died, the mean age of death was $57.43 \pm 13 \cdot 19$ years after a mean duration of $16 \cdot 82 \pm 11 \cdot 14$ years. $^{24}$

The ratio of affected to unaffected subjects from these eight families was 48:54 excluding index cases $\left(\chi^{2}=0.036, p>0.5\right)$. These figures only include subjects aged 60 or over. The sex ratio of affected persons was 42 males : 31 females $\left(\chi^{2}=1 \cdot 37\right.$, $p>0 \cdot 1)$. There were two unaffected subjects who had an affected parent or sibs and affected children. These died at the ages of 44 and 48 years. The disorder had occurred, or must have occurred, in more than two generations in seven of the families. In the eighth, an affected parent had been brought up in an orphanage and no details were known about her parents. In another, only members of two generations appeared to be affected but more than one subject had the disease in the oldest generation so there must have been an earlier gene carrier who either died young or was not known to be affected by his or her descendants. There were no families where an affected subject with affected children had normal parents who survived beyond the age of 65 . Thus there was no definite evidence of new mutation in any of the kindreds studied.

Biological fitness was calculated by comparing the mean number of offspring of index cases and that of affected subjects who had reproduced since 1928, with a theoretical value for the normal population of $2 \cdot 15$. Family size in the UK has only varied between $2 \cdot 0$ and $2 \cdot 3$ since 1928 (Registrar General). The results are shown in table 1 . Mean family size was also compared between males and females, using all the pedigree data and index cases alone.
The fitness of all the index cases was not significantly different from unity. It will be noted that females had significantly more children than males, even among the small number of index cases.

It was impossible to quantify severity in this $-\overrightarrow{0}$ disorder but the mean ages of onset of males $\frac{C}{\square}$ $\left(39 \cdot 25 \pm 10 \cdot 73\right.$ years) and females $\left(36.04 \pm 8 \cdot 40 \frac{\overline{\bar{c}}}{\bar{D}}\right.$ years) were not significantly different $(t=1 \cdot 25$, $ه$ $\mathrm{p}>0.05$ ). The mean ages of death of males $(55.33 \pm 11.22$ years) and females $(58.07 \pm 13.73 \mathrm{c}$ years) were also similar $(t=0.61, p>0.05)$. The $\vec{O}$ mean ages of onset and death of affected children $\overrightarrow{\vec{H}}$ of affected males (onset 33.53 \pm 9.71 , death $\vec{\omega}$ $45.43 \pm 14.09$ years) were significantly less than those of affected females (onset $40 \cdot 51 \pm 9 \cdot 20$, death

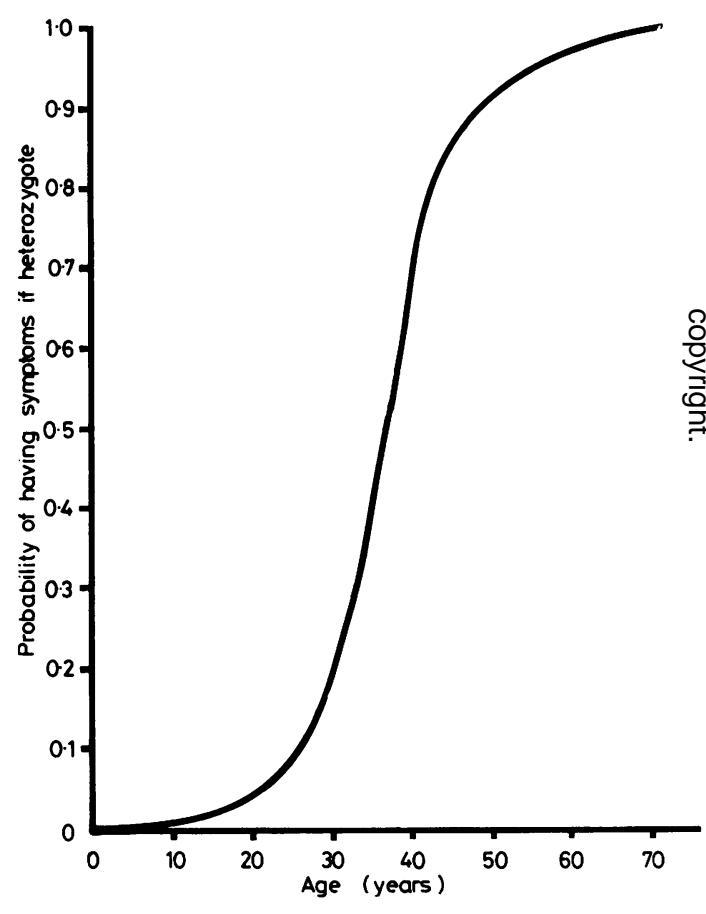

FIGURE Cumulative frequency curve of age of onset of autosomal dominant cerebellar ataxia.

TABLE 1 Autosomal dominant cerebellar ataxia with randomly associated additional features: biological fitness

\begin{tabular}{|c|c|c|c|c|c|c|}
\hline & $\begin{array}{l}\text { Index cases } \\
\text { (8) }\end{array}$ & $\begin{array}{l}\text { All cases } \\
\text { since } 1928 \\
(31)\end{array}$ & $\begin{array}{l}\text { All males } \\
(28)\end{array}$ & $\begin{array}{l}\text { All females } \\
\text { (25) }\end{array}$ & $\begin{array}{l}\text { Index males } \\
\text { (6) }\end{array}$ & $\begin{array}{l}\text { Index females } \\
\text { (2) }\end{array}$ \\
\hline $\begin{array}{l}\text { Mean family size }( \pm S D) \\
\text { Biological fitness } \\
\text { t } \\
\text { p }\end{array}$ & $\begin{array}{l}2 \cdot 25 \pm 1 \cdot 83 \\
1.05 \\
0 \cdot 15 \\
>0.5\end{array}$ & $\begin{array}{l}3 \cdot 25 \pm 2 \cdot 25 \\
1 \cdot 51 \\
2 \cdot 47 \\
<0 \cdot 02\end{array}$ & \multicolumn{2}{|c|}{$\begin{array}{l}2.74 \\
<0.01\end{array}$} & \multicolumn{2}{|c|}{$\begin{array}{l}2.68 \\
<0.05\end{array}$} \\
\hline
\end{tabular}


TABLE 2 Autosomal dominant cerebellar ataxia with randomly associated features: risks of heterozygosity based on cumulative age of onset curve

\begin{tabular}{llcl}
\hline $\begin{array}{l}\text { Age of subject at risk } \\
\text { (ie has affected parent) }\end{array}$ & $\begin{array}{l}\text { Risk to subject } \\
\text { (if unaffected) }\end{array}$ & $\begin{array}{l}\text { Risk to } \\
\text { child }\end{array}$ & $\begin{array}{l}\text { Risk to } \\
\text { grandchild }\end{array}$ \\
\hline 20 & $2 \cdot 0$ & $4 \cdot 0$ & - \\
25 & $2 \cdot 1$ & $4 \cdot 2$ & - \\
30 & $2 \cdot 3$ & $4 \cdot 6$ & - \\
35 & $2 \cdot 7$ & $5 \cdot 4$ & $10 \cdot 8$ \\
40 & $3 \cdot 9$ & $7 \cdot 8$ & $15 \cdot 6$ \\
45 & $7 \cdot 7$ & $15 \cdot 4$ & $30 \cdot 8$ \\
50 & $14 \cdot 3$ & $28 \cdot 6$ & $57 \cdot 2$ \\
55 & 27.7 & $55 \cdot 4$ & $110 \cdot 8$ \\
60 & 41 & 82 & 164 \\
65 & 81 & 162 & 324 \\
\hline
\end{tabular}

(The number given is $x$, where risk $=1 / x$ )

$56.57 \pm 8.71$ years; onset: $\mathrm{t}=2.59, \mathrm{p}<0.02$; death: $\mathrm{t}=2 \cdot 36, \mathrm{p}<0 \cdot 05$ ).

A cumulative frequency curve of age of onset in all affected subjects was constructed and is shown in the figure. Ideally, in view of the difference in age of onset between offspring of affected males and females two curves are needed, but the numbers would be small. This curve allows probability of developing the disease to be calculated for persons at risk and their children and grandchildren. These probabilities were calculated for different ages of subjects at risk using Bayes's theorem. ${ }^{29}$ The results are shown in table 2.

\section{Discussion}

There are virtually no genetic data concerning the dominantly inherited cerebellar ataxias among previously published reports, and none on age of onset of symptoms in relation to genetic counselling. This no doubt reflects the confusion in terms of classification. Also, most reports in the past have referred to single patients or families; the present series is the largest reported to date. The classification of the dominant cerebellar ataxias proposed in the introduction is, of course, at best provisional, but there is no reason to suggest that the families described here can be subdivided further on clinical or genetic grounds. Linkage studies may provide further evidence of genetic heterogeneity. There have been conflicting reports concerning linkage of the HLA locus to the locus of the gene giving rise to the disorder in similar families to those presented here. ${ }^{30-32}$

Although one of the diagnostic criteria for the group of patients under discussion was evidence of autosomal dominant inheritance, it is of interest that no examples of autosomal recessive or $\mathrm{X}$ linked recessive late onset cerebellar ataxia were encountered in the series as a whole (outlined in the
Methods section). This is in keeping with previously published reports. It thus appears that recessive late onset cerebellar ataxia is extremely rare, if it exists at all. In the kindreds described where only members of one sibship were affected, usually little or no information is given about the parents, ${ }^{33-37}$ or the parents died before reaching an age at which they would be at risk of developing the disease. ${ }^{11} 3338$ The sex ratio of affected subjects in the present series was not significantly different from 1:1 and there was no suggestion of $\mathrm{X}$ linked dominant transmission in the pedigree data. It was difficult to compare severity between affected males and females, but the ages of onset in the two sexes were not significantly different. The earlier ages of onset and death in the offspring of affected males is of considerable interest. A similar trend has been noted in relation to age of onset in Huntington's chorea. ${ }^{39} 40$ The explanation of this is unclear. The findings in the present series contrast with those of two other studies of single families, ${ }^{14} 41$ in which the offspring of affected females were thought to have an earlier onset and more rapidly progressive course than those of affected males. Statistical evidence for this was not presented.

The gene concerned in this disease appeared to be fully penetrant as all affected subjects had an affected parent, unless the parent had died before the risk period of developing the disease had elapsed or accurate information was not available. One important point, especially when considering single cases of late onset cerebellar ataxia (where genetic counselling is difficult), is that there is evidence from the current study to suggest that the frequency of new dominant mutations in this disorder is low. Firstly, the disease had been present in at least three generations in all the families studied. Usually it had occurred as far back as the patients interviewed could remember. In one family it was known to have been present in nine generations. Secondly, biological fitness was not impaired. This is not surprising as the mean age of onset occurred after the reproductive period. The age of onset, course, age of death, and preservation of biological fitness in dominantly inherited cerebellar ataxia are very similar to those of Huntington's chorea. ${ }^{42}$ It is probably reasonable to suggest that the proportion of new mutations may be similar. Mattsson ${ }^{43}$ estimated the mutation rate in Huntington's chorea to be, at most, $5 \cdot 0 \times 10^{-6}$, that is, $2.53 \%$ of all cases.

The difference in mean family size between affected males and females is interesting. The reason for this is probably related to the significant incidence $(43.7 \%)$ of dementia in this disorder. ${ }^{24}$ There can be little doubt that females have always controlled family size to a greater extent than males. 
In the presence of even mildly impaired intellectual function such control may be less strict, with a resulting increase of fitness of females. It is quite possible that impaired judgement antedates the onset of physical symptoms. Spouses of affected males, on the other hand, are not likely to reproduce more than normally. They may have fewer children than normal if they recognise the genetic implications of the presence of the disease in their husband's family. Relatively few of the patients studied had ever requested genetic counselling and a considerable proportion were not aware of the genetic risks to their offspring. Many of the patients had been diagnosed as having multiple sclerosis or Parkinson's disease in the past. Thus, on genetic grounds alone there is good reason for investigating these families in depth. It is hoped that the cumulative frequency curve for age of onset (figure) will be of use in counselling subjects at risk of developing this disorder. Certainly the risks to children of subjects at risk are diminishing to more acceptable values than 1 in 4 by the time these children are likely to reproduce. These risks could be further reduced by using the child's age in an additional Bayesian calculation based on the curve and his prior probability of developing the disease in relation to parental age.

I wish to thank the following, who kindly allowed me to study their patients: Sir Roger Bannister, Professors J Marshall and P K Thomas, Drs C J Eari, G D Perkin, R Ross-Russell, and P Rudge. Dr Robin Winter provided helpful discussion of the manuscript. Financial support from the Friedreich's Ataxia Group and the Medical Research Council is gratefully acknowledged.

\section{References}

1 Friedreich N. Uber degenerative Atrophie der spinalen Hinterstränge. Virchows Arch [Pathol Anat] 1863;26: 391-419.

2 Geoffroy G, Barbeau A, Breton A, et al. Clinical description and roentgenologic evaluation of patients with Friedreich's ataxia. Can J Neurol Sci 1976; 3:279-86.

3 Andermann E, Remillard GM, Goyer G, Blitzer L, Barbeau A. Genetic and family studies in Freidreich's ataxia. Can J Neurol Sci 1976;3:287-302.

4 Marie P. Sur l'hérédoataxie cérébelleuse. Sem Med (Paris) 1893;13:444-7.

5 Holmes G. An attempt to classify cerebellar disease, with a note on Marie's hereditary cerebellar ataxia. Brain $1907 ; 30: 545-67$.

- Greenfield JG. The spino-cerebellar degenerations. Oxford: Blackwell, 1954.

7 Konigsmark BW, Weiner LP. The olivopontocerebellar atrophies : a review. Medicine 1970;49:227-41.

8 Weiner LP, Konigsmark BW. Hereditary disease of the cerebellar parenchyma. Birth Defects 1971;7:192-6.
9 Carpenter S, Schumacher GA. Familial infantile cerebellar $\Omega$ atrophy associated with retinal degeneration. Arch Neurol $1966 ; 14: 82-94$.

10 Schut JW, Haymaker W. Hereditary ataxia: a pathologic study of five cases of common ancestry. $J$ Neuropathol Clin Neurol 1951;1:183-213.

11 Sigwald J, Lapresle J, Raverdy P, de Recondo J. Atrophie cérébelleuse familiale avec association de lesions nigériennes et spinales. Presse Med 1964;72:557-68.

12 Fergusion FR, Critchley M. A clinical study of an heredo- $\overrightarrow{\mathbb{D}}$ familial disease resembling disseminated sclerosis. Brain 1929;52:203-25.

13 Schut JW. Hereditary ataxia: clinical study through six generations. Arch Neurol Psychiatry 1950;63:535-68.

14 Pedersen L. Hereditary ataxia in a large Danish pedigree. Clin Genet $1980 ; 17: 385-93$.

15 Bell J, Carmichael EA. On hereditary ataxia and spastic paraplegia. In: Treasury of human inheritance. Vol IV, part III. London: Cambridge University Press, 1939: 141-281.

16 Gray RC Oliver CP. Marie's hereditary cerebellar ataxia $\infty$ (olivopontocerebellar atrophy). Minn Med 1941;24: 327-35.

17 Brown JW, Coleman RF. Hereditary spastic paraplegia with ocular and extrapyramidal signs. Bull Los Ang Neurol Soc 1966;31:21-34.

18 Gayle RF, Williams JP. A familial disease of the central nervous system resembling multiple sclerosis. South Med J $1933 ; 26: 242-6$.

19 Boller F, Segarra JM. Spino-pontine degeneration. Eur Neurol 1969;2:356-73.

20 Pogacar S, Ambler M, Conklin WJ, O'Neil WA, Lee HY. Dominant spinopontine atrophy: report of two additiona members of family W. Arch Neurol 1978;35:156-62.

21 Weber FP. Greenfield JG. Cerebello-olivary degeneration an example of heredo-familial incidence. Brain $1942 ; 63$ 220-31.

22 Woods BT, Schaumburg HH. Nigrospinodentatal degeneration with nuclear ophthalmoplegia. In: Vinken PJ, Bruyn GW, eds. Handbook of clinical neurology. 응 Vol 22. Amsterdam: North Holland Publishing Company, 1975:157-76.

${ }^{23}$ Healton EB, Brust JCM, Kerr DL, Resor S, Penn A. Presumably Azorean disease in a presumably nonPortugese family. Neurology (Minneap) 1980;30:1084-9.

24 Harding AE. The clinical features and classification of the late onset autosomal dominant cerebellar ataxias: a study of eleven families, including descendants of "the Drew family of Walworth'. In preparation.

25 Boudin G, Barbizet J, Le Hénaff MY. Hérédo-ataxie cérébelleuse avec amblyopie et paralysie de la verticalité du regard chez la mère et l'enfant. Rev Neurol (Paris) 1952;87:330-5.

26 Björk A, Lindblom U, Wadensten L. Retinal degeneration in hereditary ataxia. $J$ Neurol Neurosurg Psychiatry $1956 ; 19: 186-93$

27 Jampel RS, Okazaki H, Bernstein H. Ophthalmoplegia and retinal degeneration associated with spino-cerebellar ataxia. Arch Ophthalmol $1961 ; 66: 247-59$.

28 Tyrer JH. Friedreich's ataxia. In: Vinken PJ, Bruyn GW, N eds. Handbook of clinical neurology. Vol 21. Amsterdam: North Holland Publishing Company, 1975:319-64.

29 Bayes T. An essay towards solving a problem in the $\widetilde{\sigma}$ doctrine of chances. Philos Trans $R$ Soc Lond 1763;53: $376-418$.

30 Jackson JF, Currier RD, Terasaki PI, Morton NE. Spinocerebellar ataxia and HLA linkage. Risk prediction by HLA typing. $N$ Engl J Med 1977;296:1138-41. 
31 Koeppen AH, Goedde HW, Hirth L, Benkmann HG, Hiller C. Genetic linkage in hereditary ataxia. Lancet $1980 ; \mathbf{i}: 92-3$.

32 Nino HE, Noreen HJ, Dubey DP, et al. A family with hereditary ataxia: HLA typing. Neurology (Minneap) $1980 ; 30: 12-20$.

33 Aring CD. Degeneration of the basal ganglia associated with olivopontocerebellar atrophy. J Nerv Ment Dis $1940 ; 92: 448-70$.

34 Bastiaensen LAK, Jaspar HHJ, Stadhouders AM, Egberink GJM, Korten JJ. Chronic progressive external ophthalmoplegia in a heredo-ataxia: neurogenic or myogenic? Acta Neurol Scand 1977;56:483-507.

35 Brion S, De Recondo J. Ophtalmoplégie nucléaire progressive et hérédo-dégénerescence spino-cérébelleuse. Rev Neurol (Paris) 1967;116:383-400.

36 Neumann MA, Cohn R. Progressive familial ataxia. Clinical study of two brothers with one autopsy. $J$ Neuropathol Exp Neurol 1955;14:398-412.

37 Wilson G, Dean JS. Hereditary ataxia in identical twins affecting the cerebellum and certain of its physiologically related structures: a clinicopathologic study. Arch Neurol Psychiatry $1941 ; 45$ :1044-6.
38 Richter RB. A clinico-pathologic study of parenchymatous cortical cerebellar atrophy: report of familial case. J Nerv Ment Dis 1940;91:37-46.

39 Brackenridge CJ. The relation of sex of affected parent to the age of onset of Huntington's disease. J Med Genet $1973 ; 10: 333-6$.

40 Bird ED, Caro AJ, Pilling JB. A sex related factor in the inheritance of Huntington's chorea. Ann Hum Genet $1974 ; 37: 255-60$

41 Schut JW, Böök JA. Hereditary ataxia. Difference between progeny of male and female affected members and a definition of certain signs useful in detecting the disease prior to onset of clinical symptoms. Arch Neurol Psychiatry $1953 ; 70: 169-79$.

42 Pratt RTC. The genetics of neurological disorders. Oxford: Oxford University Press, 1967.

43 Mattsson B. Huntington's chorea in Sweden. 1. Prevalence and genetic data. Acta Psychiatr Scand [Suppl] $1974 ; 255: 211-9$.

Requests for reprints to Dr A E Harding, Department of Neurology, The Middlesex Hospital, Mortimer Street, London W1N 8AA. 